Mycoplasma genitalium (MG)). Proportions, medians, interquartile ranges (IOR), and 95\% confidence intervals were calculated using STATA 9.0.

Results A total of 220 FSWs were enrolled in the study. Median age was 25 years old (IOR: 21-30). Consistent condom use with clients in the last month was $81.33 \%$ (95\% CI: $74.16-87.22)$, and with occasional partners was $63.11 \%$ (95\% CI: $53.03-72.41)$. Approximately $57.27 \%$ (95\% CI: 50.45-63.9) had received an HIV test in the last 12 months. HIV prevalence was $0.91 \%(95 \%$ CI: $0.11-3.26 \%)$. The most prevalent STI was HSV-2 $(51.63 \%$, 95\% CI: 44.73-58.48), followed by CT; (19.79\%; 95\% CI: $14.33-$ $26.23)$, TV (18.18\%; 95\% CI: $12.93-24.47)$, and MG $(11.23 \%$; 95\% CI: 7.09-16.65). Syphilis and NG prevalence was observed at $<3 \%$.

Conclusions We found low prevalence of HIV in FSWs in Belize. However, risky sexual behaviours and STI prevalence remain a problem. Improved prevention strategies aimed at consistent condom use and access to HIV/STI testing are needed for the control and prevention of infections among FSW.

\section{P3.108 MOBILE GYNECOLOGICAL CLINIC - EFFECTIVE TOOL FOR HIVSTI SCREENING DIAGNOSTICS FOR COMMERCIAL SEX WORKERS IN LVIV REGION (UKRAINE)}

doi:10.1136/sextrans-2013-051184.0567

${ }^{1}$ M Vasylyev, ${ }^{1} M$ Sluzhynska, ${ }^{20}$ Sluzhynska, ${ }^{2} 0$ Grushynska, ${ }^{20}$ Krystynyak, ${ }^{2} 0$ Krystynyak, ${ }^{2} \mathrm{O}$ Krystynyak, ${ }^{2} \mathrm{O}$ Krystynyak, ${ }^{20}$ Krystynyak, ${ }^{20}$ Krystynyak. 'Lviv Regional AIDS Center, Lviv, Ukraine, ${ }^{2}$ Charitable Salus Foundation, Lviv, Ukraine

Background Since October 2008 till present time, Lviv Regional AIDS Center and Charitable Salus Foundation implement project "HIV prevention by increasing access to VCT (voluntary HIV testing and counselling), sexually transmitted infections (STI) diagnostics among commercial sex workers (CSW) in Lviv region using mobile gynaecological clinic (MGC). The initiative is supported by International HIV $\backslash$ AIDS Alliance in Ukraine.

Methods Specially equipped bus - MGC was used for this intervention. MGC works daily except Saturday and Sunday visiting highest HIV rate places all over Lviv region (2.5 million population) providing CSW with condoms, lubricants, information materials and rapid testing for HIV, syphilis, gonorrhoea, Chlamydia, hepatitis B and C. Shampoos, lipsticks, hand creams were distributed among CSW as a motivation for those clients who passed HIV \STI test.

Results During October 2008 - January 201312059 visits were done by CSW. 4031 rapid HIV test were made (197 positive results) 2886 rapid syphilis tests (37 positive results) 2133 tests for gonorrhoea (30 positive results) 2133 tests for Chlamydia (230 positive results) 1499 Hepatitis B tests (63 positive results) 1499 Hepatitis C tests (141 positive results)

Conclusions Taking into consideration obtained data such intervention is very needed and welcomed by key population representatives. Gender oriented approach in HIV prevention programmes for female sex workers is very important factor for the success of the intervention In great importance continuation of performed services and spreading the range of activities such as tuberculosis diagnostics, access to medications for treatment in MGC.

\section{P3.109 VARIABILITY IN THE DETERMINANTS AND PREVALENCE OF HIV AND SYPHILIS AMONG FEMALE SEX WORKERS IN TWO NEIGHBOURING DISTRICTS IN NORTH KARNATAKA INDIA}

doi:10.1136/sextrans-2013-051184.0568

${ }^{1}$ R G Washington, ${ }^{2} \mathrm{~N}$ Chandiok, 'P Banandur, ${ }^{1} \mathrm{~A}$ Krishnamurthy, ${ }^{1} \mathrm{G}$ Pise. ${ }^{1} \mathrm{KHPT}$, Bangalore, India; ${ }^{2}$ CMR, New Delhi, India
Background Districts in north Karnataka have the highest HIV prevalence and female sex worker (FSW) to male population ratio in India. We examined the variability in socio-cultural, behavioural and clinical determinants contributing to HIV and syphilis prevalence in two neighbouring north Karnataka districts.

Methods FSW recruited from targeted intervention clinics responded to an oral questionnaire, underwent clinical examination and provided a blood sample for HIV and syphilis testing. We conducted univariate and multivariate logistic regression with HIV and syphilis as outcomes and with age, place of residence, marital status, literacy, monthly income, alcohol use, age at sexual debut and commercial sex work, clientele over the past week and STI syndromes as variables.

Results 1545 and 1551 FSW were recruited in the two districts. HIV ( $8 \%$ vs $6 \%$ ) and syphilis prevalence ( $3 \%$ vs $1 \%$ ) was significantly higher in district A. District A had significantly higher proportions of rural residents ( $92 \%$ vs $81 \%$ ), devadasi ( $67 \%$ vs $15 \%$ ), illiteracy ( $80 \%$ vs $64 \%$ ), higher income (Rs6000 vs Rs 5000 ), clientele per week (6 vs 4 ) and STI syndromes (16\% vs $7 \%$ ). While age at sexual debut was similar in both districts, significantly higher proportion in district $A$ initiated sex work below the age of $15(26 \%$ vs $11 \%)$. Alcohol consumption was higher in B (15\% vs $3 \%)$. The odds of being HIV positive was significantly higher amongst FSWs with income > Rs5000 per month (AOR 1.61), being devadasi (AOR $2.43)$, consuming alcohol (AOR 1.64), h/o STI syndrome in the past 6 months (AOR 1.97) or clinically with an STI (1.95).

Conclusion Despite being neighbouring districts with similar socio-demographic backgrounds, significant variability in the prevalence of HIV and syphilis is perhaps contributed by the variability in prevalence of specific socio-cultural factors, behaviours and clinical syndromes of STI.

\section{P3.110 RELATIONSHIP BETWEEN VIOLENCE AND HIV INFECTION AMONG FEMALE SEX WORKERS IN BENIN}

doi:10.1136/sextrans-2013-051184.0569

1,2F K Tounkara, ${ }^{3} \mathrm{~F}$ Guédou, ${ }^{4} \mathrm{C}$ Ahoussinou, ${ }^{5} \mathrm{D}$ M Zannou, ${ }^{6} \mathrm{~A}$ Kpatchavi, ${ }^{7} \mathrm{D}$ D Kintin, ${ }^{8} \mathrm{~L}$ Avery, ${ }^{9} \mathrm{E}$ Bédard, ${ }^{1,2} \mathrm{R}$ Bitera, 1,2M Alary. 'Département de médecine sociale et préventive, Université Laval, Quebec, OC, Canada; ${ }^{2} U R E S P$, Centre de recherche du CHU, Quebec, OC, Canada; 'ispensaire des Infections Sexuellement Transmissibles (DIST), Cotonou, Benin; ${ }^{4}$ Programme nationale de lutte contre le Sida et les IST, Cotonou, Benin; ${ }^{5} 5$ Faculté des Sciences de la Santé, Université d'Abomey-Calavi, Cotonou, Benin; ${ }^{6}$ Département de sociologie, Université d'Abomey-Calavi, Cotonou, Benin; 'Bureau d'appui en santé publique (BASP'96), Cotonou, Benin; ${ }^{8}$ Faculty of

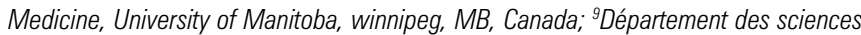
infirmières, Université du Québec à Rimouski, Campus Lévis, Lévis, OC, Canada

Objective In Africa, there are few studies examining female sex workers (FSWs) vulnerability to physical, sexual and psychological violence and how this influences their HIV risk. This study sought to assess the types, frequency and factors associated with violence among FSWs and examined the relationship between violence and HIV prevalence.

Methods Data from an integrated biological and behavioural survey (Benin, 2012), were used to analyse the frequency of physical, sexual and psychological violence. We also created a violence score using the number of violence types experienced by FSWs. Multivariable logistic regression analysis controlling for potential socio-demographic and behavioural confounders was used to assess the association between violence and HIV.

Results Among the 1016 FSWs recruited in this survey, 17.1\%, $13.3 \%$ and $33.4 \%$ reported having experienced, at least once in the past 30 days, physical, sexual and psychological violence, respectively. Condom breakage was strongly and significantly associated with all 3 types of violence $(P<0.0001)$. HIV prevalence was $20.39 \%$. In the multivariable analysis, the adjusted odds ratio (AOR) for the 